\title{
Antimicrobial activity of zinc and titanium dioxide nanoparticles against biofilm-producing methicillin-resistant Staphylococcus
} aureus

\author{
A. Jesline $\cdot$ Neetu P. John $\cdot$ P. M. Narayanan • \\ C. Vani $\cdot$ Sevanan Murugan
}

Received: 29 October 2013/Accepted: 28 February 2014/Published online: 13 March 2014

(C) The Author(s) 2014. This article is published with open access at Springerlink.com

\begin{abstract}
Methicillin-resistant Staphylococcus aureus (MRSA) is one of the major nosocomial pathogens responsible for a wide spectrum of infections and the emergence of bacterial resistance to antibiotics has lead to treatment drawbacks towards large number of drugs. Formation of biofilms is the main contributing factor to antibiotic resistance. The development of reliable processes for the synthesis of zinc oxide nanoparticles is an important aspect of nanotechnology today. Zinc oxide and titanium dioxide nanoparticles comprise well-known inhibitory and bactericidal effects. Emergence of antimicrobial resistance by pathogenic bacteria is a major health problem in recent years. This study was designed to determine the efficacy of zinc and titanium dioxide nanoparticles against biofilm producing methicillin-resistant $S$. aureus. Biofilm production was detected by tissue culture plate method. Out of 30 MRSA isolates, 22 isolates showed strong biofilm production and 2 showed weak and moderate biofilm formation. Two strong and weak biofilm-producing methicillinresistant $S$. aureus isolates were subjected to antimicrobial activity using commercially available zinc and titanium dioxide nanoparticles. Thus, the nanoparticles showed considerably good activity against the isolates, and it can be concluded that they may act as promising, antibacterial agents in the coming years.
\end{abstract}

A. Jesline · N. P. John · P. M. Narayanan · C. Vani .

S. Murugan $(\square)$

Department of Biotechnology, School of Biotechnology and

Health Sciences, Karunya University, Karunya Nagar,

Coimbatore 641114, Tamil Nadu, India

e-mail: micromurugans@gmail.com
Keywords Biofilms - Zinc oxide nanoparticles . Titanium oxide nanoparticles - Antimicrobial activity . Methicillin-resistant Staphylococcus aureus

\section{Introduction}

Methicillin-resistant Staphylococcus aureus (MRSA) is one of the major nosocomial pathogens responsible for a wide spectrum of infections which includes skin and soft tissue infections, pneumonia, bacteraemia, surgical site infections (SSI), and catheter-related infections (De San et al. 2007; Emily and Trish 2011). The emergence of bacterial resistance to antibiotics and its distribution are major health problems that lead to treatment failure for a large number of drugs (Julian and Dorothy 2010). Biofilm formation is the main contributing factor to bacterial antibiotic resistance. Staphylococcus aureus becomes resistant by producing an extracellular polymeric substance (EPS) matrix that is composed of polysaccharides, nucleic acids, proteins and lipids (Davey and O'Toole 2000; Kokare et al. 2009). Sessile bacteria embedded in this EPS matrix are able to withstand the host immune responses and thereby become less susceptible to antibiotics, which in turn fail to penetrate inside the biofilm. Therefore, there is an urgent clinical need to develop novel antibacterial therapies to destroy biofilms which will henceforth, reduce healthcare infections. Nanostructured materials are attracting a great deal of consideration because of their capability and selectivity, particularly in biological and pharmaceutical applications (Wu et al. 2003; Fortner et al. 2005; Li et al. 2005). The most studied aspects of nanotechnology field are its ability to tussle bacterial infections through the production of nanoparticles (Luo et al. 2007). The antimicrobial activities of metal oxide nanoparticles and their selective toxicity to biological systems suggest their potential 
applications as therapeutics, diagnostics, surgical devices and nanomedicine-based antibacterial agents (Sawai 2003; Laura et al. 2006; Reddy et al. 2007; Sobha et al. 2010). The compensation of using these metal oxides' nanoparticles as antimicrobial agents is their better efficiency on resistant bacteria, less toxicity and heat resistance, and among metal oxide nanoparticles, $\mathrm{ZnO}$ nanoparticles have many significant features such as chemical and physical stability, high catalysis activity and effective antibacterial activity (Kalyani et al. 2006; Matei et al. 2008). Titanium dioxide nanoparticles $\left(\mathrm{TiO}_{2}\right)$ decompose organic compounds by the formation and constant release of hydroxyl radicals and superoxide ions when exposed to non-lethal ultraviolet (UV) light, which is highly efficient in inhibiting the growth of MRSA (Shah et al. 2008). This potent oxidizing power of $\mathrm{TiO}_{2}$ NPs typically results in case of bacteria and other organic substances (Cho et al. 2005; Fujishima et al. 2000; Shiraishi and Hirai 2008). The small nanometer-scale $\mathrm{TiO}_{2}$ and $\mathrm{ZnO}$ nanoparticles impose several effects that govern its antibacterial action. Thus, the present study was designed to evaluate the antibacterial activity of $\mathrm{ZnO}$ and $\mathrm{TiO}_{2}$ NPs against biofilm-producing MRSA isolates.

\section{Materials and methods}

The present study was conducted in the Department of Biotechnology, Karunya University, Coimbatore, India, from December 2010 to May 2011.

\section{$\mathrm{ZnO}$ and $\mathrm{TiO}_{2}$ NPs}

Commercially synthesized $\mathrm{ZnO}$ and $\mathrm{TiO}_{2}$ NPs were purchased from Sigma-Aldrich, St. Louis, MO. The reported "as manufactured" sizes were: ZnO NPs $<100 \mathrm{~nm}$ and $\mathrm{TiO}_{2}$ NPs $<50 \mathrm{~nm}$. The subsequent dilutions were made in autoclaved double-distilled water.

Preparation of $\mathrm{ZnO}$ NPs and $\mathrm{TiO}_{2}$ NPs suspension (Ansari et al. 2009)

One hundred milligrams of $\mathrm{ZnO}$ NPs and $\mathrm{TiO}_{2}$ NPs was added to $10 \mathrm{ml}$ of sterile MQ water and shaken vigorously. The suspending solution was treated by ultrasound $(100 \mathrm{w}$, $40 \mathrm{kHz}$ ) for $30 \mathrm{~min}$, autoclaved at $121{ }^{\circ} \mathrm{C}$ for $20 \mathrm{~min}$ and then cooled down to room temperature. The reason for the use of sonication was to break down the agglomerates and aggregation of nanoparticles and make their dispersions.

Bacterial isolates, medium and cultivation

The bacterial isolates from the clinical specimens were isolated and characterized as MRSA and were used as test organisms to evaluate the antimicrobial effects of $\mathrm{ZnO}$ and $\mathrm{TiO}_{2}$ NPs. All the isolates were cultured aerobically at $37{ }^{\circ} \mathrm{C}$ on Mueller-Hinton Agar (MHA) plates, Hi-Media (Mumbai, India).

Antibiotic susceptibility testing

The antibiotic susceptibility pattern was determined by modified Kirby Bauer disc diffusion method against the following antibiotics (drug concentration in $\mu \mathrm{g}$ ): amoxyclav (30), ampicillin (10), ampicillin/sulfbactam (10/10), cefoxitin (30), co-trimoxazole (25), clindamycin (2), chloramphenicol (30), ciprofloxacin (30), fusidic acid (30), gentamicin (10), levofloxacin (10), linezolid (30), minocycline (30), mupirocin (5), ofloxacin (5), rifampicin (5), teicoplanin (30), tetracycline (30) and vancomycin (30). The Mueller-Hinton agar (MHA) plate supplemented with $2 \% \mathrm{NaCl}$ was swabbed with MRSA culture with turbidity matching $0.5 \mathrm{McF}$ arland standard, by a sterile cotton swab and the antibiotics discs were laid on the surface (CLSI 2012).

Detection of biofilm production

Overnight grown bacterial culture in trypticase soya broth (TSB) supplemented with $1 \%$ glucose was diluted 1:100 and $200 \mu \mathrm{l}$ of the bacterial culture was inoculated in 96-well flat bottom polystyrene microtitre plates (Tarsons, India) (Christensen et al. 1985). Incubation was carried out at $35^{\circ} \mathrm{C}$ for $24 \mathrm{~h}$. Cultures were then aspirated and the wells were washed three times with phosphate-buffered saline, $\mathrm{pH}$ 7.2. The plates were then air dried overnight and stained with $0.1 \%$ crystal violet. The optical density of the wells was measured at $570 \mathrm{~nm}$ using micro-ELISA auto reader. An optical density of $<0.120$ for nonbiofilm producer, 0.120-0.240 for moderate biofilm producer, and $>0.240$ was chosen to distinguish strong biofilm producers. Sterile TSB was used as a negative control (blank). To compensate for background absorbance, the OD reading value of blank was deducted from the test values. Intensity of biofilm was classified as given by Mathur et al. (2006).

Determination of antimicrobial activity

by well-diffusion method

The $\mathrm{ZnO}$ and $\mathrm{TiO}_{2}$ NPs were tested for antimicrobial activity by well-diffusion method against strong and weak biofilm-producing MRSA. The pure cultures of MRSA were subcultured onto sterile Luria-Bertani broth and incubated at $37{ }^{\circ} \mathrm{C}$ for $16-18 \mathrm{~h}$. After $16-18 \mathrm{~h}$, the optical density of the above inoculated culture was checked to be around 0.1 at $600 \mathrm{~nm}$ to obtain $1 \times 10^{8} \mathrm{CFU} / \mathrm{ml}$. Wells of 6-mm diameter were made on Mueller-Hinton agar plates using gel puncture. Each strain was swabbed uniformly 
Fig. 1 Antimicrobial susceptibility pattern of methicillin-resistant $S$. aureus ( $A$ ampicillin, $A C$ amoxyclav, $A$ / $S$ ampicillin/sulfbactam, $C O T$ co-trimoxazole, $C D$

clindamycin, $C L$

chloramphenicol, $C I P$

ciprofloxacin, $F C$ fusidic acid, $G$ gentamicin, $L E$ levofloxacin, $L Z$ linezolid, MIN minocycline, $M U$ mupirocin, $O F$ ofloxacin,

$R I F$ rifampicin, $T E I$ teicoplanin, TET tetracycline,

$V$ vancomycin, $C X$ cefoxitin)

Table 1 Screening for biofilm production by MRSA using tissue culture plate method

\begin{tabular}{llll}
\hline Organism & OD values & & \\
\cline { 2 - 4 } & $\begin{array}{lll}(>0.240) \\
+++(\%)\end{array}$ & $\begin{array}{l}(0.120-0.240) \\
++(\%)\end{array}$ & $\begin{array}{l}(<0.120) \\
-(\%)\end{array}$ \\
\hline MRSA & $22(73.33)$ & $4(13.33)$ & $4(33.33)$ \\
$(n=30)$ & & & \\
\hline
\end{tabular}

$(+++)$ strongly, $(++)$ moderate, $(-)$ weak

onto the individual plates using sterile cotton swabs. Using a micropipette, 100, 200 and $500 \mu \mathrm{g} / \mathrm{ml}$ of $\mathrm{ZnO}$ and $\mathrm{TiO}_{2}$ nanoparticles solution was poured onto each of three wells on all plates. After incubation at $35{ }^{\circ} \mathrm{C}$ for $18 \mathrm{~h}$, the different levels of zone of inhibition were measured.

\section{Results}

Antibiotic susceptibility testing

All the isolates subjected to the study exhibited varying resistance patterns against 19 commonly used antibiotics. Vancomycin was found to be the most effective drug overall against MRSA as none of the tested isolates exhibited resistance against it. However, cefoxitin, ampicillin, gentamicin and co-trimoxazole developed $100 \%$ resistance rendering them incapable to act as effective drugs. The percentage of resistance to antibiotics such as chloramphenicol, ciprofloxacin, ofloxacin, amoxyclav, linezolid, tetracycline, teicoplanin, clindamycin, rifampicin, fusidic acid, mupirocin, amoxycillin/sulfbactam, levofloxacin and minocycline was found to be in the order of $95,90,83,80,76$, 70, 67, 60, 57, 57, 50, 44, 43 and $36 \%$, respectively (Fig. 1).

Detection of biofilm production

All the MRSA isolates were subjected to the standard TCP assay and 22 tested isolates displayed biofilm positive phenotype in TSB medium, after incubation for 18 and $24 \mathrm{~h}$, respectively. Optical density (OD) of stained adherent bacteria was determined with a micro-ELISA auto reader (model 680, Bio-Rad) at wavelength of $570 \mathrm{~nm}$ (Table 1).

Antibiotic-resistant patterns of biofilm and nonbiofilm-producing MRSA

Antibiotic-resistant patterns of biofilm and nonbiofilmproducing MRSA isolates are illustrated in Fig. 2. All the biofilm-producing isolates showed $100 \%$ resistance to cefoxitin followed by tetracycline, chloramphenicol, ciprofloxacin, co-trimoxazole, amoxyclav, gentamicin and ampicillin. Both biofilm producer and nonbiofilm producer exhibited $100 \%$ resistance to cefoxitin followed by gentamicin, ampicillin and co-trimoxazole. However, resistance to other antibiotics such as linezolid (54 vs. $47 \%$ ), teicoplanin (73 vs. $47 \%$ ), minocycline (64 vs. $57 \%$ ), mupirocin (73 vs. $63 \%$ ), ofloxacin (64 vs. $57 \%$ ), clindamycin (64 vs. $42 \%$ ), fusidic acid ( 81 vs. $42 \%$ ), amoxycillin/sulfbactam (45 vs. $36 \%$ ), levofloxacin ( 81 vs. $57 \%$ ), and rifampicin (45 vs. $42 \%$ ) was comparatively higher among biofilm producers than among nonbiofilm producers. Resistance among biofilm producers to ciprofloxacin was also higher (100 vs. $47 \%)$ when compared with nonbiofilm producers.

Antimicrobial activity of $\mathrm{ZnO}$ and $\mathrm{TiO}_{2}$ NPs against MRSA

The antimicrobial activity of $\mathrm{ZnO}$ and $\mathrm{TiO}_{2}$ NPs was investigated against biofilm-producing MRSA using welldiffusion method. The mean of four replicates of the diameter of inhibition zones (in millimeters) around each well with $\mathrm{ZnO}$ and $\mathrm{TiO}_{2}$ NPs solution is represented in Table 2. It was found that at all concentrations, $\mathrm{ZnO}$ NPs were able to inhibit bacterial growth and a maximum zone of inhibition of 16 and $17 \mathrm{~mm}$ at $500 \mu \mathrm{g} / \mathrm{ml}$ and a 
Fig. 2 Antibiotic-resistant patterns of biofilm and nonbiofilm-producing, methicillin-resistant $S$. aureus ( $A$ ampicillin, $A C$ amoxyclav, $A$ / $S$ ampicillin/sulfbactam, $C O T$ co-trimoxazole, $C D$ clindamycin, $C L$

chloramphenicol, $C I P$ ciprofloxacin, $F C$ fusidic acid, $G$ gentamicin, $L E$ levofloxacin, $L Z$ linezolid, MIN minocycline, $M U$ mupirocin, $O F$ ofloxacin, $R I F$ rifampicin, $T E I$ teicoplanin, TET tetracycline, $C X$ cefoxitin)

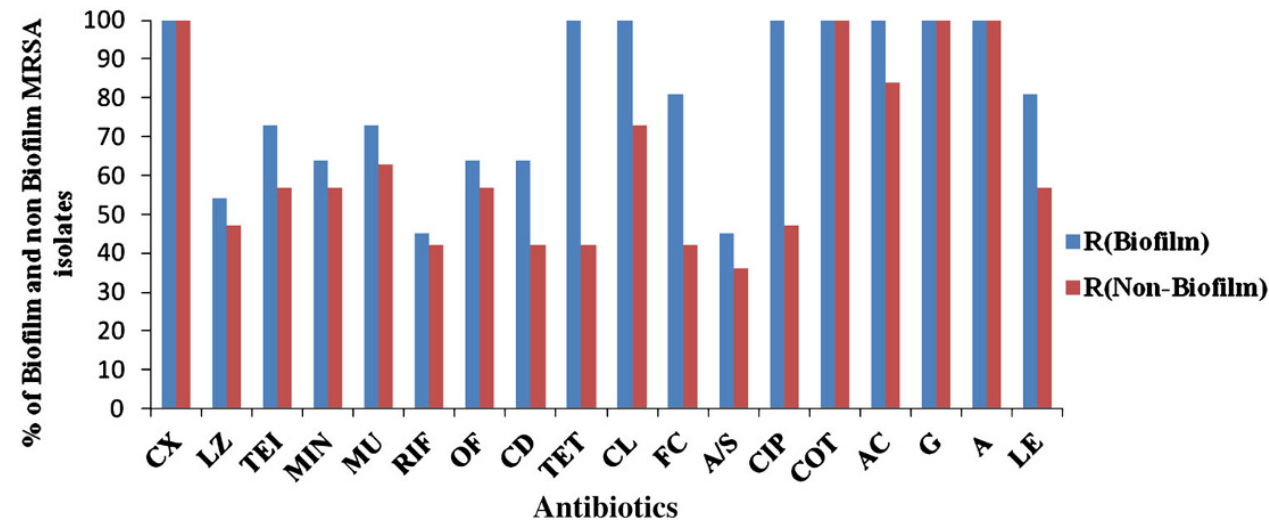

Table 2 Zone of inhibition of $\mathrm{ZnO}$ and $\mathrm{TiO}_{2}$ NPs against biofilm-producing MRSA

\begin{tabular}{|c|c|c|c|c|c|c|c|c|}
\hline \multirow[t]{3}{*}{ Study no. } & \multirow{3}{*}{$\begin{array}{l}\text { MRSA } \\
\text { isolates }\end{array}$} & \multirow{3}{*}{$\begin{array}{l}\text { Biofilm } \\
\text { forming capacity }\end{array}$} & \multicolumn{6}{|c|}{ Zone of diameter in $\mathrm{mm}$ (mean of four replicates) } \\
\hline & & & \multicolumn{3}{|l|}{$\mathrm{ZnO} \mathrm{NPs}$} & \multicolumn{3}{|l|}{$\mathrm{TiO}_{2} \mathrm{NPs}$} \\
\hline & & & $100(\mu \mathrm{g} / \mathrm{ml})$ & $200(\mu \mathrm{g} / \mathrm{ml})$ & $500(\mu \mathrm{g} / \mathrm{ml})$ & $100(\mu \mathrm{g} / \mathrm{ml})$ & $200(\mu \mathrm{g} / \mathrm{ml})$ & $500(\mu \mathrm{g} / \mathrm{ml})$ \\
\hline 1 & SA 2 & Strong & 12 & 14.5 & 16 & 11 & 13.5 & 14 \\
\hline 2 & SA 6 & Weak & 14 & 16 & 17 & 12 & 13 & 14 \\
\hline
\end{tabular}

minimum zone of inhibition of 12 and $14 \mathrm{~mm}$ at $100 \mu \mathrm{g} / \mathrm{ml}$ were observed against strong and weak biofilm-producing MRSA isolates, respectively. Similarly, $\mathrm{TiO}_{2} \mathrm{NPs}$ were able to inhibit bacterial growth and a maximum zone of inhibition of $14 \mathrm{~mm}$ at $500 \mu \mathrm{g} / \mathrm{ml}$ and a minimum zone of inhibition of 11 and $12 \mathrm{~mm}$ at $100 \mu \mathrm{g} / \mathrm{ml}$ were observed against strong and weak biofilm-producing MRSA isolates, respectively.

\section{Discussion}

MRSA has the ability to form biofilms, which contribute to antibiotic resistance and other related infections (Paintsil 2007; Kwon et al. 2008). In this study, $73.3 \%$ of MRSA isolates were found to produce biofilms. This is comparatively higher than 14.7, 52.7 and $56.6 \%$ as reported by Mathur et al. (2006); Gundogan et al. (2011) and Zmantar et al. (2009). The present study employed the TCP method for the detection of biofilm in MRSA. It is the easiest and cheapest technique available for routine laboratory use (Ruzicka et al. 2010). We compared the differences in antibiotic-resistant patterns between the biofilm and nonbiofilm-producing MRSA isolates. Cha et al. (2011) suggested that biofilms are more resistant to killing than planktonic cells are which supports the findings of the present study. Cha et al. (2011) demonstrated that daptomycin and tigecycline activities in biofilms were better than those of the other conventional antibiotics (vancomycin, clindamycin, gentamicin, and linezolid). But, in the present study, vancomycin, ampicillin/sulfbactam, rifampicin and linezolid antibiotics showed better activities against biofilms. Shrestha et al. (2009) found that MRSA isolates were susceptible to vancomycin, teicoplanin and linezolid, whereas in this study, we observed complete susceptibility against vancomycin only and resistance to teicoplanin and linezolid.

Zinc oxide has a very good potential to move into the clinical field (Shopsin et al. 1999). The antibacterial activity of ZnO NPs against many isolates has been well documented like in Staphylococcus spp. (Huang et al. 2008), K. pneumoniae (Lee, 2009), and Pseudomonas spp. (Jiang et al. 2009), Escherichia coli (Zhang et al. 2009). Rizwan et al. (2010) have stated that when the concentration of $\mathrm{ZnO}$ nanoparticles is increased it resulted in the augmenting of zone size. Whereas in this study, there was no significant difference in the zone of inhibition at 100 and $200 \mu \mathrm{g} / \mathrm{ml}$, but there was an increase in size at $500 \mu \mathrm{g} / \mathrm{ml}$. Ansari et al. (2009) reported that employing increased concentration of $\mathrm{ZnO}$ NPs, did not show any steady increase in the zone size. Previous researchers have proposed that release of $\mathrm{H}_{2} \mathrm{O}_{2}$ might be one of the possible mechanisms for antibacterial activity of ZnO-NPs (Yamamoto 2001; Yamamoto et al. 2004). The toxicity of $\mathrm{ZnO}$ and of other metal oxides towards human beings is observed at higher concentrations, but low concentrations of $\mathrm{ZnO}$ are non-toxic towards human cells. The occurrence of insoluble zinc in the well-diffusion agar method clearly indicates the antibacterial activity of $\mathrm{ZnO}$ NPs. On the other hand, $\mathrm{ZnO}$ NPs are much more effective in 
controlling the growth of various microorganisms (Sawai 2003).

Gelover et al. (2006) reported that $\mathrm{TiO}_{2}$ NPs are the mostly studied for their photocatalytic antimicrobial activity among various NPs. Roy et al. (2010) in their study suggested that $\mathrm{TiO}_{2}$ NPs failed to exhibit antibacterial activity, but upon combination with antibiotics they were able to inhibit the growth of microorganisms. But here, $\mathrm{TiO}_{2}$ NPs without any kind of combination inhibited the growth of MRSA isolates with a maximum zone of $14 \mathrm{~mm}$ at $500 \mu \mathrm{g} / \mathrm{ml}$ and a minimum zone of 11 and $12 \mathrm{~mm}$ at $100 \mu \mathrm{g} / \mathrm{ml}$ against strong and weak MRSA isolates. Zhang et al. (2009) have suggested the possible mechanisms involving the interaction of nanomaterials with the biological molecules. The author documented that microorganisms carry a negative charge while metal oxides carry a positive charge which creates an "electromagnetic" attraction between the microbe and treated surface concluding that once the contact is made, the microbe is oxidized and dead instantly (Zhang and Chen 2009).

Thus, the antimicrobial activity of the nanoparticles showed that the $\mathrm{ZnO}$ and $\mathrm{TiO}_{2}$ NPs have great potential to be used as antimicrobial agents against microorganisms. Resistance to antimicrobial agents by pathogenic bacteria has emerged in recent years and it is a major health problem. This study would serve as a useful guidance for the physicians and also other healthcare-associated workers for the choice of antibiotics and nanoparticles in the treatment of MRSA biofilm infections. But ZnO NPs and $\mathrm{TiO}_{2}$ NPs inhibited the growth with a maximum zone of inhibition of $16 \mathrm{~mm}$ (strong), $17 \mathrm{~mm}$ (weak) and $14 \mathrm{~mm}$ (for both strong and weak) at $500 \mu \mathrm{g} / \mathrm{ml}$, respectively, against biofilm producing MRSA isolates. The study confirmed that strong MRSA biofilm had increased resistance to most of the antibiotics. Therefore, there is a need for a better understanding of the properties of MRSA biofilmmediated diseases. For instance, the development of metallic nanoparticles covering the surfaces of ambulatory and other medical devices would provide an alternative means to decrease the microorganism colonization and device-associated infection, including ventilator-associated pneumonia, central venous catheter infections and catheterassociated urinary tract infections.

Acknowledgments The authors would like to express their gratitude to Dr. Paul Dinakaran, Chancellor, Dr. S. Sundar Manoharan, Vice Chancellor, Rev. (Dr.) Sarvjeet Herbert, Pro Vice-Chancellor, Dr. Joseph Kennady, Registrar, Dr. Patrick Gomez, Director (SBT \& HS), and Dr. Jannet Vennila, Head, Department of Biotechnology, Karunya University, Coimbatore for providing the necessary facilities for carrying out the work. Also, the authors would like to thank Head of the Department (Microbiology Division) of Diagnostic Laboratories and Mr. Mahendran (Microbiologist) for providing the cultures for the study.
Open Access This article is distributed under the terms of the Creative Commons Attribution License which permits any use, distribution, and reproduction in any medium, provided the original author(s) and the source are credited.

\section{References}

Ansari MA, Haris MK, Aijaz AK, Asfia S, Ameer A (2009) Synthesis and characterization of the antibacterial potential of $\mathrm{ZnO}$ nanoparticles against extended-spectrum $\beta$-lactamases-producing E. coli and $K$. pneumoniae isolated from a tertiary care hospital of North India. Appl Microbiol Biotech 10:3733-3736

Cha S, Sood A, Prasad K, Wahner-Roedler D (2011) Patients' preferences about participation in clinical trials studying complementary and alternative medicine. Altern Therap Health Med 17(6):36-42

Cho K, Park J, Osaka T, Park S (2005) The study of antimicrobial activity and preservative effects of nanosilver ingredient. Electrochim Acta 51:956-960

CLSI (2012) Performance standards for antimicrobial disc susceptibility tests. Approved standard 11th edn, CLSI 2012; document M02-A11

Davey ME, O'Toole GA (2000) Microbial biofilms: from ecology to molecular genetics. Microbiol Mol Biol Rev 64(4):847-867

de San N, Denis O, Gasasira MF, De Mendonca R, Nonhoff C, Struelens MJ (2007) Controlled evaluation of the IDI-MRSA assay for detection of colonization by methicillin-resistant, Staphylococcus aureus in diverse mucocutaneous specimens. A J Clin Microbiol 45(4):1098-1101

Emily RMS, Trish MP (2011) Hospital epidemiology and infection control in acute-care settings. Clin Microbiol Rev 24(1):141-173

Fortner JD, Lyon DY, Sayes CM, Boyd AM, Falkner JC, Hotze EM, Alemany LB, Tao YJ, Guo W, Ausman KD, Colvin VL, Hughes JB (2005) C-60 in water: nanocrystal formation and microbial response. Environ Sci Technol 39(11):4307-4316

Fujishima A, Rao TN, Tryk DA (2000) Titanium dioxide photocatalysis. J Photochem Photobiol C: Photochem Rev 1(1):1-21

Gelover S, Gomez LA, Reyes K, Teresa M (2006) A partial demonstration of water disinfection using $\mathrm{TiO}_{2}$ films and sunlight. Water Res 40(17):3274-3278

Gundogan E, Tukek T, Cikrikcioglu MA, Halac G, Hursitoglu M, Erkal H, Cakirca M, Kinas BE, Erek A, Yetmis M (2011) Prevalence of gluten sensitive enteropathy antibodies in restless legs syndrome. Acta Neurol Belg 111(4):282-286

Huang Z, Zheng X, Yan D, Yin G, Liao X, Kang Y, Yao Y, Huang D, Hao B (2008) Toxicological effect of $\mathrm{ZnO}$ nanoparticles based on bacteria. Langmuir 24:4140-4144

Jiang W, Hamid M, Baoshan X (2009) Bacterial toxicity comparison between nano- and micro-scaled oxide particles. Environ Pollut 157(5):1619-1625

Julian D, Dorothy D (2010) Origins and evolution of antibiotic resistance. Microbiol Mol Biol Rev 74(3):417-433

Kalyani G, Anil VG, Bo-Jung C, Yong-Chien L (2006) Preparation and characterization of $\mathrm{ZnO}$ nanoparticles coated paper and its antibacterial activity study. J Green Chem 8:1034-1041

Kokare CR, Chakraborty S, Khopade AN, Mahadik KR (2009) Biofilm: importance and applications. Ind J Biotech 8:159-168

Kwon AS, Park GC, Ryuc SY, Lim DH, Lime DY, Choi CH, Park Y, Lim Y (2008) Higher biofilm formation in multidrug-resistant clinical isolates of S. aureus. J Antimicrob Agents Chemother 32:68-72

Laura KA, Delina YL, Pedro JJA (2006) Comparative eco-toxicity of nanoscale $\mathrm{TiO}_{2}, \mathrm{SiO}_{2}$, and $\mathrm{ZnO}$ water suspensions. J Water Res 40:3527-3532

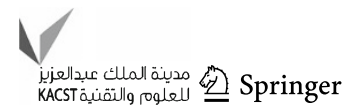


Lee S (2009) Multifunctionality of layered fabric systems based on electrospun polyurethane/zinc oxide nanocomposite fibers. J Appl Polymer Sci 114(6):3652-3658

Li P, Li J, Wu C, Wu Q, Li J (2005) Synergistic antibacterial effects of lactams antibiotic combined with silver nanoparticles. Nanotechnol 16(9):1912-1917

Luo PG, Tzeng TR, Shah RR, Stutzenberger FJ (2007) Nanomaterials for antimicrobial applications and pathogen detection. Cur Trends in Microbiol 3:111-128

Matei A, Cernica I, Cadar O, Roman C, Schiopu V (2008) Synthesis and characterization of $\mathrm{ZnO}$ : polymer nanocomposites. Int $\mathrm{J}$ Mater Form 1:767-770

Mathur T, Singhal S, Khan S, Upadhyay DJ, Fatma T, Rattan A (2006) Detection of biofilm formation among the clinical isolates of Staphylococci: an evaluation of three different screening methods. Ind J Med Microbiol 24(1):25-29

Paintsil E (2007) Pediatric community-acquired methicillin-resistant $S$. aureus infection and colonization: trends and management. Curr Opin Pediatr 19:75-82

Reddy KM, Kevin F, Jason B, Denise GW, Cory H, Alex P (2007) Selective toxicity of zinc oxide nanoparticles to prokaryotic and eukaryotic systems. J Appl Phy Lett 90:1-3

Rizwan W, Young-Soon K, Amrita M, Soon-Il Y, Hyung-Shik Sh (2010) Formation of $\mathrm{ZnO}$ micro-flowers prepared via solution process and their antibacterial activity. J Nanoscale Res Lett 5(10):1675-1681

Roy A, Ameena P, Anil K, Ambika PMVN (2010) Effect of nanotitanium dioxide with different antibiotics against methicillinresistant $S$. aureus. J Biomater Nanobiotech 1:37-41

Ruzicka F, Holaav Votava M, Tejkalova R, Horvat R, Heroldova M, Woznicova V (2010) Biofilm detection and the clinical significance of Staphylococcus epidermidis isolates. Folia Microbiol 49(5):596-600

Sawai J (2003) Quantitative evaluation of antibacterial activities of metallic oxide powders $(\mathrm{ZnO}, \mathrm{MgO}$ and $\mathrm{CaO})$ by conductimetric assay. J Microbiol Methods 54:177-182
Shah MSA, Nag M, Kalagara T, Singh S, Manorama SV (2008) Silver on PEG-PU-TiO2 polymer nanocomposite films; an excellent system for antibacterial applications. Chem Materials 20(7):2455-2460

Shiraishi Y, Hirai T (2008) Selective organic transformations on titanium oxide-based photocatalysts. J Photochem Photobiol C: Photochem Rev 9:157-170

Shopsin B, Gomez M, Montgomery OS, Smith DH, Waddington M, Dodge DE, Bost DA, Riehman M, Naidich S, Kreiswirth BN (1999) Evaluation of protein a gene polymorphic region DNA sequencing for typing of Staphylococcus aureus strains. J Clin Microbiol 37:3556-3563

Shrestha B, Pokhrel BM, Mohapatra TM (2009) Antibiotic susceptibility pattern of nosocomial isolates of $S$. aureus in a tertiary care hospital, Nepal. J Nepal Med Assoc 48(175):234-238

Sobha K, Surendranath K, Meena V, Jwala KT, Swetha N, Latha KSM (2010) Emerging trends in nanobiotechnology. J Biotechnol Mol Biol Rev 5:1-12

Wu X, Liu H, Liu J, Haley KN, Treadway JA, Larson JP, Ge N, Peale F, Bruchez MP (2003) immunofluorescent labelling of cancer marker Her2 and other cellular targets with semiconductor quantum dots. Nat Biotechnol 21(1):41-46

Yamamoto $O$ (2001) Influence of particle size on the antibacterial activity of zinc oxide. Intern J Inorg Mat 3:643-646

Yamamoto O, Komatsu M, Sawai J, Nakagawa ZE (2004) Effect of lattice constant of zinc oxide on antibacterial characteristics. J Mat Sci Mat Med 15:847-851

Zhang H, Chen G (2009) Potent antibacterial activities of $\mathrm{Ag} / \mathrm{TiO} 2$ nanocomposite powders synthesized by a one-pot sol-gel method. Environ J Sci Technol 43(8):2905-2910

Zhang G, Breuer M, Forster A, Adam DE, Wodarz A (2009) Mars, Drosophila protein related to vertebrate HURP, is required for the attachment of centrosomes to the mitotic spindle during syncytial nuclear divisions. J Cell Sci 122:535-545

Zmantar T, Kouidhi B, Miladi H, Bakhrouf A (2009) Detection of macrolide and disinfectant resistance genes in clinical $S$. aureus and coagulase-negative Staphylococci. BMC Res Notes 4:453 